\title{
Detection of novel strains of cyprinid herpesvirus closely related to koi herpesvirus
}

\author{
Marc Y. Engelsma ${ }^{1}$, Keith Way $^{2}$, Melanie J. Dodge ${ }^{2}$, Michal Voorbergen-Laarman ${ }^{1}$, \\ Valentina Panzarin ${ }^{3}$, Miriam Abbadi ${ }^{3}$, Mansour El-Matbouli ${ }^{4}$, Helle Frank Skall ${ }^{5}$, \\ Søren Kahns ${ }^{5,6}$, David M. Stone ${ }^{2, *}$ \\ ${ }^{1}$ Central Veterinary Institute (CVI), part of Wageningen UR, PO Box 65, 8200 AB Lelystad, The Netherlands \\ ${ }^{2}$ Cefas, Barrack Road, The Nothe, Weymouth, Dorset DT4 8UB, UK \\ ${ }^{3}$ Istituto Zooprofilattico Sperimentale delle Venezie (IZSVe), Viale dell'Universita 10, 35020 Legnaro, Padova, Italy \\ ${ }^{4}$ University of Veterinary Medicine, Vienna, Veterinärplatz 1, 1210 Vienna, Austria \\ ${ }^{5}$ National Veterinary Institute (DTU-Vet), Technical University of Denmark, Hangøvej 2, 8200 Aarhus N, Denmark \\ ${ }^{6}$ Present address: Danish Technological Institute, Kongsvang Allé 29, 8000 Aarhus C, Denmark
}

\begin{abstract}
Cyprinid herpesvirus 3 (CyHV-3) or koi herpesvirus (KHV) is a devastating virus of carp. Using generic primers for the DNA polymerase and the major capsid protein genes of cyprinid herpesviruses, nucleotide sequences divergent from previously described CyHV-3 were obtained. At least 3 novel groups of putative CyHV-3-like viruses were identified, sharing 95 to $98 \%$ nucleotide identity with CyHV-3 strains. Carp carrying the CyHV-3 variants did not show clinical signs consistent with CyHV-3 infection and originated from locations with no actual CyHV-3 outbreaks. These strains might represent low- or non-pathogenic variants of CyHV-3.
\end{abstract}

KEY WORDS: Carp $\cdot$ Alloherpesviridae $\cdot$ Phylogeny $\cdot$ CyHV-3 $\cdot$ Variant strains

\section{INTRODUCTION}

The culture of common carp Cyprinus carpio L. accounts for a significant part of global aquaculture (Bostock et al. 2010). Viral agents, and among these viral species of the family Alloherpesviridae, genus Cyprinivirus, can form a serious threat to cultured and wild carp populations worldwide. Papillomatous skin lesions of carp have been described in carp ponds in Europe since the Middle Ages (Wolf 1988). The causative agent, carp pox herpesvirus or cyprinid herpesvirus 1 (CyHV-1), was identified as a virus belonging to the herpes group in the 1950s (Schubert 1966) and first isolated a few decades later (Sano et al. 1985). Although mortalities can be evoked in carp fry (Sano et al. 1991), in general the effect of the disease on its host is limited and is primarily a problem in the cultivation of ornamental carp because of the focal epidermal hyperplasia. On the other hand, koi herpesvirus disease (KHVD) is a recently emerging and lethal disease of koi and common carp, with cyprinid herpesvirus 3 (CyHV-3) as the causative agent (Waltzek et al. 2005, 2009). Since the first description of KHVD by Hedrick et al. (1999), the virus has rapidly emerged at a global scale (Haenen et al. 2004). The disease has triggered serious mortalities among carp cultured for consumption (Sano et al. 2004, Sunarto et al. 2005, Bergmann et al. 2006, Hara et al. 2006) and ornamental purposes (Hedrick et al. 2000, Sunarto et al. 2005). CyHV-3 has been acknowledged as an economically and sociologically important pathogen, and KHVD has been placed on the list of serious diseases notifiable to the World Organisation for Animal Health (OIE) and the European Union (EU). Both CyHV-1 and CyHV-3 are closely related to the 
third member of the genus Cyprinivirus, the haematopoietic necrosis herpesvirus of goldfish or cyprinid herpesvirus 2 (CyHV-2), which specifically infects goldfish Carassius auratus (Jung \& Miyazaki 1995, Davison et al. 2013).

The complete genome sequences of $3 \mathrm{CyHV}-3$ isolates (KHV-U, KHV-I and TUMST1) originating from different geographical locations show only limited differences among each other (Aoki et al. 2007) and share more than 99\% DNA sequence identity over the complete genomes (Avarre et al. 2011). Recent papers have described some degree of genetic variability between CyHV-3 isolates based upon nucleotide polymorphisms in specific regions of the genome and variation in the variable number of tandem repeats (VNTRs; Bigarré et al. 2009, Kurita et al. 2009, Avarre et al. 2011). In general, the variability between CyHV-3 strains, particularly in the welldefined open reading frames, is limited, whereas the VNTRs could prove to be valuable markers for epidemiological studies aimed at identifying the source of disease outbreaks.

In the present study, novel CyHV DNA sequences were detected in carp and koi tissues by application of generic PCR primers capable of detecting a wide range of cyprinid herpesviruses. The $\mathrm{CyHV}$ sequences suggest that infections have occurred with viruses closely related to CyHV-3 but yet genetically distinguishable. A preliminary molecular characterisation of the novel cyprinid herpesviruses was carried out, and the sequences were compared with other herpesviruses from fish.

\section{MATERIALS AND METHODS}

The material used in this study was taken as part of a surveillance programme or routine diagnostic testing of diseased carp and koi in the UK, Austria, Italy and the Netherlands from 2006 to 2012. Gill and kidney tissues were sampled from common carp/koi carp and stored in absolute ethanol. Total DNA was extracted from approximately $20 \mathrm{mg}$ of tissue using the QIAamp DNA Mini Kit (Qiagen) or $50 \mu \mathrm{l}$ of a clarified $10 \%$ tissue homogenate prepared for virus culture using the QIAamp virus mini Kit (Qiagen) following the manufacturer's protocol. The DNA was eluted in a 50 and a $60 \mu$ volume, respectively. Purified DNA samples were stored at $-20^{\circ} \mathrm{C}$ until further processing.

The primers used in this study are shown in Table 1. The thymidine kinase (TK) primers KHVTKf and KHV-TKr have already been published by Bercovier et al. (2005). The CyHV primers were designed to anneal conserved regions of the DNA polymerase and major capsid protein (MCP) genes of CyHV-1 to -3 , identified by alignment of published sequences.

Samples from koi and common carp were routinely screened for the presence of CyHV-3 using the KHVTKf and KHV-TKr primer set. The PCR assay was performed in 4 different laboratories (CVI, Cefas, IZSVe, DTU-Vet) under slightly different conditions. Essentially, the protocols were run with the GeneAmp 9700 (Applied Biosystems) or the DNA Engine Tetrad ${ }^{\circledR} 2$ thermal cycler (BioRad) using the following conditions: $95^{\circ} \mathrm{C}$ for $2 \mathrm{~min}, 40$ cycles of $95^{\circ} \mathrm{C}$ for $30 \mathrm{~s}, 55^{\circ} \mathrm{C}$ for $30 \mathrm{~s}, 72^{\circ} \mathrm{C}$ for 30 to $45 \mathrm{~s}$ and a final extension step of $72^{\circ} \mathrm{C}$ for 7 to $10 \mathrm{~min}$. Each reaction contained $1 \times$ concentrated PCR buffer, 1.5 to $2.5 \mathrm{mM}$ $\mathrm{MgCl}_{2}, 0.2 \mathrm{mM}$ of each deoxynucleotide, $0.2 \mu \mathrm{M}$ of each primer KHV-TKf and KHV-TKr and 2 units of Taq DNA Polymerase in nuclease-free water. A volume of 2.5 or $5 \mu$ l of extracted DNA was added to the reaction mix to make a final volume of $50 \mu \mathrm{l}$. The amplification products were resolved with electrophoresis using a $2 \%$ agarose gel and visualised under UV light.

Table 1. Oligonucleotide sequences used in this study. CyHV: cyprinid herpesvirus; KHV: koi herpesvirus

\begin{tabular}{|llcl|}
\hline Name & Sequence $\left(5^{\prime}-3^{\prime}\right)$ & Amplicon (bp) & Target \\
\hline $\begin{array}{l}\text { CyHVpolfor } \\
\text { CyHVpolrev }\end{array}$ & CCA GCA ACA TGT GCG ACG G & 361 & Generic CyHV DNA polymerase \\
CyHVpolforint & CGA CGG VGG YAT CAG CCC & 339 & gene \\
CyHVpolrevint & GAG TTG GCG CAY ACY TTC ATC & & \\
CyHVMCPfor1 & CAG ACC AAG AAC TAC GTG GG & 612 & Generic CyHV major capsid \\
CyHVMCPfor2 & GTC TAY GAC CAG ATG ACC ATG & 519 & protein gene \\
CyHVMCPrev & GCT CAS CAM CGC GGT GTG & & CyHV-3 thymidine kinase gene \\
KHV-TKf & GGG TTA CCT GTA CGA G & 409 & (Bercovier et al. 2005) \\
KHV-TKr & CAC CCA GTA GAT TAT GC & & \\
\hline
\end{tabular}


In parallel, a nested PCR was performed using a generic CyHV DNA polymerase primer set, CyHVpolfor - CyHVpolrev. The amplification conditions of the first-round PCR assay were the same as those described above. Where no amplification products were generated, a second round of amplification was performed using CyHVpolforint and CyHVpolrevint and 2.5 to $5 \mu$ l of the initial PCR reaction as a template.

After purification with a QIAquick PCR Purification Kit (Qiagen), PCR products were sequenced in both directions using an ABI Prism BigDye v 1.1 Terminator Cycle Sequencing kit (Applied Biosystems) and the same primers as used for the amplification. Sequence data were analysed on either an ABI Prism 3100 or 3130 Avant Genetic Analyzer (Applied Biosystems). The sample from Austria was sent to DNA Technology A/S (Risskov, Denmark) for sequencing.

\section{RESULTS AND DISCUSSION}

In cases where samples tested positive for CyHV-3 using the TK primer set, they also yielded positive results using the CyHVpol primers, and sequence analysis showed $100 \%$ nucleotide identity with the published sequences for the CyHV-3 TK and the DNA polymerase gene, respectively. However, the current study focuses only on samples testing negative for CyHV-3 when using the TK gene-specific primers, and positive when using the CyHV polymerase genespecific primers. This was observed for only a small number of the total cases tested for CyHV-3 between 2006 and 2012, which was approximately $0.75 \%$ of the cases (13 out of 1723) in the UK, and 1.3\% (25 out of 1926) of the cases in the Netherlands. Notably, most animals did not show any clinical signs, and only a few exhibited some of the clinical signs normally attributed to a CyHV-3 infection (Table 2).

In total, 33 new CyHV partial DNA polymerase sequences were successfully amplified and sequenced for samples that tested negative for CyHV-3 using the TK-specific primer set (Table 2).

The sequences were aligned and compared to sequences of CyHV-1 to -3 publicly available in GenBank. The phylogenetic tree was inferred with the maximum likelihood method, and nucleotide and amino acid identities were estimated using the MEGA 5.0 software (Tamura et al. 2011). The phylogenetic analysis showed that the newly sequenced CyHV strains are genetically correlated to CyHV-3 but still distinguishable, suggesting the presence of novel CyHV variants (Fig. 1). The CyHV-3 variant sequences were distributed within 3 clusters.
The cluster arbitrarily named CyHV-3-var1 includes samples from the Netherlands, as well as strains 3468/10:1/3 from Austria and P074 from UK, differing in 1 nucleotide from Dutch samples. Samples in this cluster share 99.7 to $100 \%$ nucleotide identity and $100 \%$ amino acid identity with each other (Table 3). Notably, strains of CyHV-3-var1 cluster collected in the Netherlands, derived from imported Japanese koi, are identical, suggesting that they originated from a single source or closely related sources. With the exception of samples P074 and M104, the cluster arbitrarily named CyHV-3var2 comprises all of the samples collected in the UK (including viruses originating from Germany) and the $\mathrm{CyHV}$ strain detected in Italy, sharing 99.0 to $99.7 \%$ nucleotide identity and 98 to $100 \%$ amino acid identity with each other. Sequences of clusters CyHV-3-var1 and CyHV-3-var2 share 97.3 to $98.3 \%$ nucleotide identity and 98 to $100 \%$ amino acid identity with each other. The third cluster, arbitrarily named CyHV-3-var3, consists of samples M104 and CVI12007066-24. These samples were identical to each other and shared 95.7 to $96.3 \%$ nucleotide identity and 96 to $98 \%$ amino acid identity with cluster CyHV-3-var2 sequences, and 97.7 to $98.0 \%$ nucleotide identity and $97 \%$ amino acid identity with sequences of cluster CyHV-3-var1. Cluster CyHV-3var3 was most closely related to the CyHV-3 group with $98.3 \%$ nucleotide identity and $99 \%$ amino acid identity with KHV sequences. Nucleotide identity calculated between the CyHV-3/CyHV-3-var1 cluster and the CyHV-3/CyHV-3-var2 cluster is 97.3 to $97.7 \%$ and 95.3 to $96.0 \%$, respectively. Amino acid identity calculated between the $\mathrm{CyHV}-3 / \mathrm{CyHV}-3-$ var1 cluster and the CyHV-3/CyHV-3-var2 cluster is 98 and 97 to $99 \%$, respectively.

To strengthen our initial findings, samples representative of the different clusters were also screened using an MCP gene-specific primer set designed to anneal sequences conserved between CyHV-1, -2 and -3 (Table 1). Amplification and sequencing were performed as described previously. An identity matrix (Table A1) and a phylogenetic tree (Fig. A1) of the MCP sequences are shown in the Appendix. These results are comparable to those obtained for the DNA polymerase gene sequences. Sequences from cluster CyHV-3-var1 share 96.5 and 97.4\% nucleotide identity with sequences from clusters CyHV-3-var2 and CyHV-3-var3, respectively. Sequences from the CyHV-3-var2 cluster share 96.1 to $96.3 \%$ nucleotide identity with sequences from the CyHV-3-var3 cluster. Sequences belonging to cluster CyHV-3-var1 were most closely related to CyHV-3, with $97.4 \%$ 
Table 2. Overview of samples used in this study. MCP: major capsid protein; KHV: koi herpesvirus

\begin{tabular}{|c|c|c|c|c|c|c|}
\hline Sample ID & County & $\begin{array}{c}\text { Date of } \\
\text { sampling } \\
\text { (dd/mm/yyyy) }\end{array}$ & Origin (fish) & $\begin{array}{l}\text { Clinical signs } \\
\text { of disease }\end{array}$ & $\begin{array}{c}\text { GenBank acc } \\
\text { DNA } \\
\text { polymerase }\end{array}$ & $\begin{array}{l}\text { on number } \\
\mathrm{MCP}\end{array}$ \\
\hline 3468/10: $1 / 3$ & Austria & 2010 & Farmed koi, imported from Israel & No clinical signs & KF148066 & \\
\hline 12ITT-426 & Italy & $28 / 09 / 2012$ & $\begin{array}{l}\text { Common carp, imported } \\
\text { from Croatia }\end{array}$ & $\begin{array}{l}\text { Mucus on gills. } \\
\text { Adhesions on the } \\
\text { internal organs }\end{array}$ & KC835198 & KC835199 \\
\hline CVI08013228-7 & Netherlands & $20 / 06 / 2008$ & Farmed koi, direct import Japan & No clinical signs & KC768197 & KC768216 \\
\hline CVI09019189-6 & Netherlands & $16 / 11 / 2009$ & Farmed koi, direct import Japan & No clinical signs & KC768198 & KC768217 \\
\hline CVI10008722-18 & Netherlands & $26 / 05 / 2010$ & Farmed koi, direct import Japan & No clinical signs & KC768199 & KC768218 \\
\hline CVI10008722-28 & Netherlands & $26 / 05 / 2010$ & Farmed koi, direct import Japan & No clinical signs & KC768200 & \\
\hline CVI10011977-6 & Netherlands & $19 / 07 / 2010$ & Farmed koi, direct import Japan & No clinical signs & KC768201 & \\
\hline CVI11007624-18 & Netherlands & $29 / 04 / 2011$ & Farmed koi, direct import Japan & No clinical signs & KC768202 & \\
\hline CVI11007624-30 & Netherlands & $29 / 04 / 2011$ & Farmed koi, direct import Japan & No clinical signs & KC768203 & \\
\hline CVI11008473-6 & Netherlands & $12 / 05 / 2011$ & Farmed koi, direct import Japan & No clinical signs & KC768204 & \\
\hline CVI11009323-15 & Netherlands & $20 / 05 / 2011$ & Farmed koi, direct import Japan & No clinical signs & KC768205 & KC768219 \\
\hline CVI11009323-18 & Netherlands & $20 / 05 / 2011$ & Farmed koi, direct import Japan & No clinical signs & KC768206 & \\
\hline CVI11010576-15 & Netherlands & $10 / 06 / 2011$ & Farmed koi, direct import Japan & No clinical signs & KC768207 & \\
\hline CVI11011470-2 & Netherlands & $24 / 06 / 2011$ & Farmed koi, direct import Japan & No clinical signs & KC768208 & \\
\hline CVI11011470-4 & Netherlands & $24 / 06 / 2011$ & Farmed koi, direct import Japan & No clinical signs & KC768209 & \\
\hline CVI12007066-24 & Netherlands & $30 / 03 / 2012$ & Farmed koi, direct import Japan & No clinical signs & KC768210 & KC768222 \\
\hline CVI12007769-24 & Netherlands & 06/04/2012 & Farmed koi, direct import Japan & No clinical signs & KC768211 & \\
\hline CVI12008701-13 & Netherlands & $20 / 04 / 2012$ & Farmed koi, direct import Japan & No clinical signs & KC768212 & KC768223 \\
\hline CVI12010203-27 & Netherlands & $21 / 05 / 2012$ & Farmed koi, direct import Japan & No clinical signs & KC768214 & KC768226 \\
\hline CVI12011935-21 & Netherlands & $15 / 06 / 2012$ & Farmed koi, direct import Japan & No clinical signs & KC768215 & KC768224 \\
\hline J177 & UK & $25 / 05 / 2006$ & Common carp, fishery & No clinical signs & KC790346 & \\
\hline J241 & UK & $21 / 06 / 2006$ & Koi, garden pond & No clinical signs & KC790345 & \\
\hline K237 & UK & $19 / 08 / 2007$ & Common carp, fishery & $\begin{array}{l}\text { Abrasion lesions } \\
\text { only }\end{array}$ & KC790344 & \\
\hline L114 & UK & $30 / 05 / 2008$ & Common carp, fishery & No clinical signs & KC790343 & \\
\hline L139 & UK & $16 / 08 / 2008$ & Common carp, fishery & No clinical signs & KC790342 & \\
\hline L171 & UK & $17 / 04 / 2008$ & Common carp, fishery & No clinical signs & KC790341 & \\
\hline M104 & UK & 2009 & & No clinical signs & KC790340 & \\
\hline P039 & UK & $21 / 04 / 2011$ & Common carp, fishery & Fungal patches & KC790339 & \\
\hline P074 & UK & 09/07/2011 & Koi, retailer; fish from Israel & $\begin{array}{l}\text { Some clinical signs } \\
\text { consistent with } \\
\text { KHV infection }\end{array}$ & KC790338 & \\
\hline P115 & UK & 04/08/2011 & Common carp, fishery & $\begin{array}{l}\text { Mucus on gills. } \\
\text { Adhesions on the } \\
\text { internal organs }\end{array}$ & KC790337 & \\
\hline P119 & UK & 05/08/2011 & Common carp, fishery & $\begin{array}{l}\text { Pale gills with } \\
\text { limited necrosis }\end{array}$ & KC790336 & \\
\hline CTL 91-3 & UK & $10 / 11 / 2008$ & Common carp from Germany & No clinical signs & KC790347 & \\
\hline CTL $90-7$ & UK & $10 / 11 / 2008$ & Common carp from Germany & No clinical signs & KC790348 & \\
\hline
\end{tabular}

nucleotide identity and $98.8 \%$ amino acid identity. Nucleotide identity calculated between the CyHV3/CyHV-3-var2 cluster and the CyHV-3/CyHV-3var3 cluster was 96.1 and $94.9 \%$, respectively.

Using generic primers for cyprinid herpesviruses on a variety of carp and koi tissue samples, partial sequences of the DNA polymerase and the MCP genes were obtained, representing putative viral strains closely related to CyHV-3 that would not be detected using the OIE recommended assay based on the TK gene. The DNA polymerase gene is among the most conserved genes between Alloherpesviridae (van Beurden et al. 2010), and therefore it is likely that overall identity at the genome level between variant strains described herein and CyHV-3 will be much lower. Although a number of attempts have been made, isolation of the putative CyHV-3-var viruses using cell culture (CCB-cell line) was unsuccessful (M. Y. Engelsma \& D. M. Stone unpubl. obs.). Although the reasons for this 


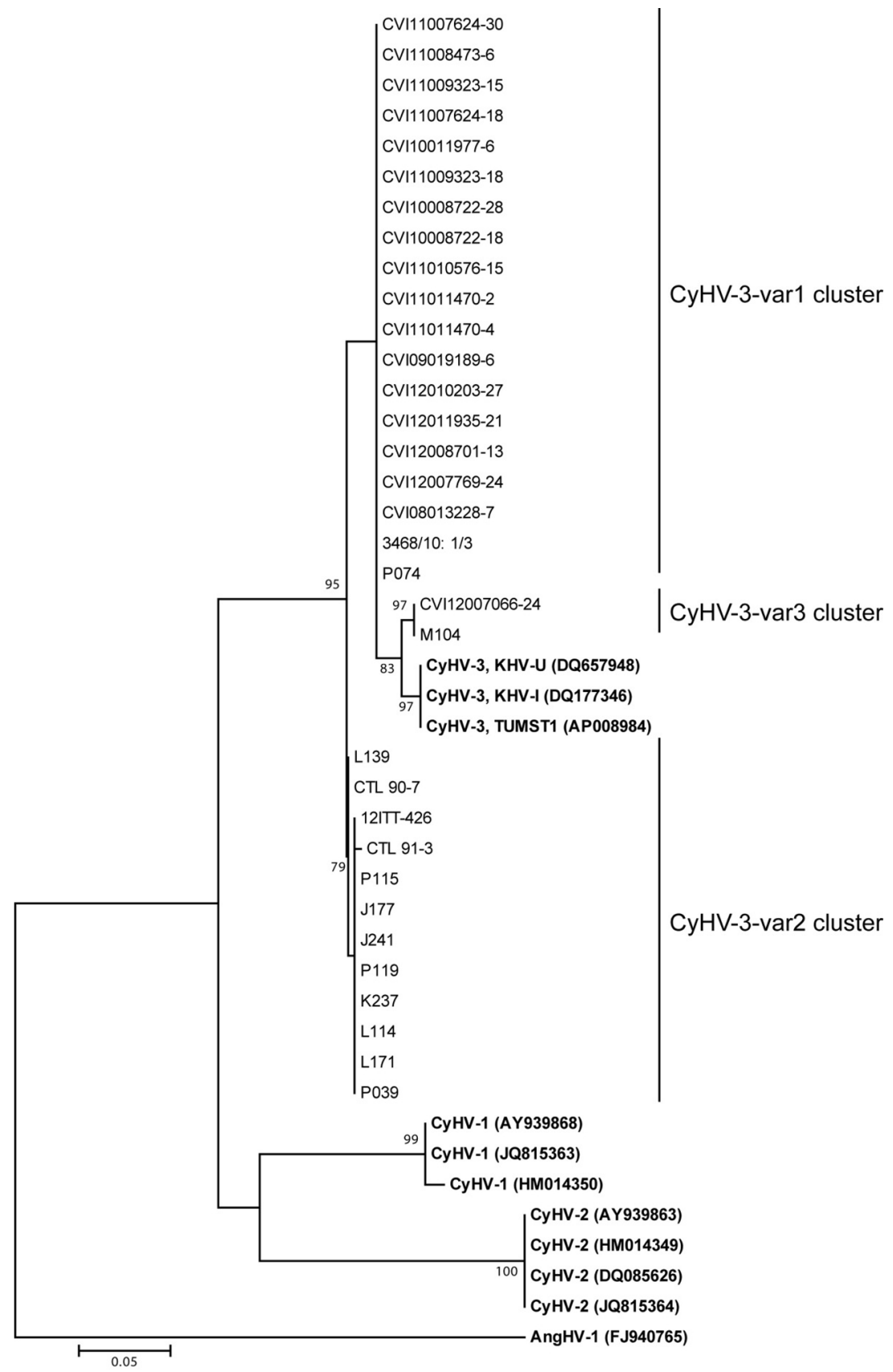

Fig. 1. Phylogenetic tree of partial DNA polymerase gene sequence. Unrooted maximum likelihood tree based on partial (300 nt) DNA polymerase gene sequences of the putative cyprinid herpesvirus (CyHV) strains. The tree with the highest log likelihood is shown. Bootstrap values (1000 replicates) of $>70 \%$ are indicated at the branch nodes. The scale bar represents the number of nucleotide substitutions per site. The known cyprinid herpesviruses are in bold, with GenBank accession numbers in brackets

are unknown, it is well recognised that the host and tissue specificity of many herpesviruses makes them recalcitrant to cell culture, and as a consequence, significant numbers of disease-causing herpesviruses remain uncharacterised (Hanson et al. 2011).
The implications of the novel CyHV strains for common carp are not known, and further research on the pathogenicity of the novel strains is hampered by the inability to culture the virus. However, most of the novel CyHV variants were detected in apparently healthy animals. Only in a few cases the animals exhibited signs usually attributed to a CyHV3 infection. This suggests either that the animals are asymptotic carriers or survivors of infection with low virus loads or that the variants represent low-pathogenic strains of CyHV-3 that do not warrant control in the same way as conventional CyHV-3 isolates. Although such viruses may not pose a serious disease threat to carp, the existence of viruses that are closely related to CyHV-3 could have a serious impact on surveillance programmes, especially when using molecular methods where the specificity is different from the assay based on the TK gene.

How we treat the variants that show a more distant genetic relationship to CyHV-3 is less clear, but in the absence of well-defined clinical signs of disease or increased mortalities associated with the virus, it is unlikely that the attempts to stamp out the virus in carrier populations through culling would be an appropriate action.

The failure of the novel strains to yield a result with the TK-PCR method suggests that the TK primer set is specific for CyHV-3, and the failure to detect the variants is presumably caused by a mismatch of the primers for the TK gene of the variant strains. The TK gene has shown to be one of the factors determining the virulence of CyHV-3 (Costes et al. 2008). Hence, further studies on the TK gene of the CyHV-3 variant strains would be of considerable interest from the perspective of diagnostics as well as its role in the pathogenicity of CyHV-3 strains. 
Table 3. Identity between partial DNA polymerase gene sequences (300 nt) of a selected number of the cyprinid herpesvirus 3 (CyHV-3) variant strains and known sequences of cyprinid herpesviruses and anguillid herpesvirus (AngHV-1). Expressed as percentage nucleotide identity (regular font) and deduced amino acid identity (in bold). Calculated using MEGA5. GenBank accession numbers of reference strains: CyHV-3 (KHV-U), DQ657948; CyHV-1, AY939868, CyHV-2, AY939863 and AngHV-1, FJ940765

\begin{tabular}{|c|c|c|c|c|c|c|c|c|c|c|c|c|}
\hline & $\begin{array}{c}\mathrm{CyHV} \\
-3\end{array}$ & $\begin{array}{l}\text { CVI1200 } \\
7066-24\end{array}$ & $\begin{array}{l}3468 / \\
10: 1 / 3\end{array}$ & $\begin{array}{c}\text { CVI0801 } \\
3228-7\end{array}$ & J177 & $\begin{array}{l}12 \mathrm{ITT} \\
-426\end{array}$ & $\begin{array}{l}\text { CTL } \\
91-3\end{array}$ & $\begin{array}{l}\text { CTL } \\
90-7\end{array}$ & L139 & $\begin{array}{c}\text { CyHV } \\
-1\end{array}$ & $\begin{array}{c}\mathrm{CyHV} \\
-2\end{array}$ & $\begin{array}{c}\text { AngHV } \\
-1\end{array}$ \\
\hline CyHV-3 & & 99.0 & 98.0 & 98.0 & 99.0 & 98.0 & 99.0 & 98.0 & 97.0 & 83.0 & 88.0 & 59.0 \\
\hline CVI12007066-24 & 98.3 & & 97.0 & 97.0 & 98.0 & 97.0 & 98.0 & 97.0 & 96.0 & 82.0 & 87.0 & 58.0 \\
\hline $3468 / 10: 1 / 3$ & 97.7 & 98.0 & & 100.0 & 99.0 & 98.0 & 99.0 & 100.0 & 99.0 & 83.0 & 86.0 & 58.0 \\
\hline CVI08013228-7 & 97.3 & 97.7 & 99.7 & & 99.0 & 98.0 & 99.0 & 100.0 & 99.0 & 83.0 & 86.0 & $\mathbf{5 8 . 0}$ \\
\hline J177 & 96.0 & 96.3 & 97.7 & 98.0 & & 99.0 & 100.0 & 99.0 & 98.0 & 84.0 & 87.0 & 59.0 \\
\hline 12ITT-426 & 95.7 & 96.0 & 97.3 & 97.7 & 99.7 & & 99.0 & 98.0 & 99.0 & 84.0 & 87.0 & 59.0 \\
\hline CTL_91-3 & 95.7 & 96.0 & 97.3 & 97.7 & 99.7 & 99.3 & & 99.0 & 98.0 & 84.0 & 87.0 & 59.0 \\
\hline CTL_90-7 & 95.7 & 96.0 & 98.0 & 98.3 & 99.7 & 99.3 & 99.3 & & 99.0 & 83.0 & 86.0 & 58.0 \\
\hline L139 & 95.3 & 95.7 & 97.7 & 98.0 & 99.3 & 99.7 & 99.0 & 99.7 & & 83.0 & 86.0 & 58.0 \\
\hline CyHV-1 & 83.0 & 82.3 & 83.0 & 82.7 & 83.3 & 83.3 & 83.0 & 83.3 & 83.3 & & 84.0 & 58.0 \\
\hline CyHV-2 & 77.7 & 78.3 & 79.0 & 78.7 & 79.3 & 79.0 & 79.7 & 79.3 & 79.0 & 79.0 & & 59.0 \\
\hline AngHV-1 & 68.0 & 67.0 & 66.7 & 67.0 & 66.7 & 66.7 & 66.3 & 66.3 & 66.3 & 64.7 & 62.7 & \\
\hline
\end{tabular}

Overall, this study highlights the potential for the existence of CyHV-3 variants that may not be detected using the conventional TK-PCR method and the value of using more generic approaches when screening for the presence of potential pathogens. However, it should also be noted that the CyHVpol PCR assay was primarily used in the UK in cases where some signs of disease were present and/or the animals were likely to be stressed, and therefore the current data cannot be used to estimate the prevalence of $\mathrm{CyHV}-3$ in carp populations in the countries concerned. Further sequencing is required to establish the true genetic relationship of the novel strains to CyHV-3, and surveillance programmes are needed to determine their prevalence and distribution throughout Europe. Most importantly, information is required on the pathogenicity of the novel strains for cyprinids to assess the risk that they pose to carp production and wild cyprinid fish species.

Acknowledgements. We thank I. Roozenburg for technical assistance in the analyses of the samples from the Netherlands, M. B. Christophersen for technical assistance in the analysis of the Austrian isolate and N. J. Olesen for critical reading of the draft manuscript. The work of M.Y.E., H.F.S and S.K. for this study was partly supported by the EU Network of Excellence Programme, EPIZONE (FOOD-CT-2006016236). The work undertaken by D.M.S., K.W. and M.J.D. was supported by Defra-funded projects F1180 and F1191.

\section{LITERATURE CITED}

Aoki T, Hirono I, Kurokawa K, Fukuda H and others (2007) Genome sequences of three koi herpesvirus isolates representing the expanding distribution of an emerging dis- ease threatening koi and common carp worldwide. J Virol 81:5058-5065

- Avarre JC, Madeira JP, Santika A, Zainun Z and others (2011) Investigation of Cyprinid herpesvirus-3 genetic diversity by a multi-locus variable number of tandem repeats analysis. J Virol Methods 173:320-327

Bercovier H, Fishman Y, Nahary R, Sinai S and others (2005) Cloning of the koi herpesvirus (KHV) gene encoding thymidine kinase and its use for a highly sensitive PCR based diagnosis. BMC Microbiol 5:13

Bergmann SV, Kempter J, Sadowski J, Fichtner D (2006) First detection, confirmation and isolation of koi herpesvirus (KHV) in cultured common carp (Cyprinus carpio L.) in Poland. Bull Eur Assoc Fish Pathol 26:97-104

Bigarré L, Baud M, Cabon J, Antychowicz J and others (2009) Differentiation between Cyprinid herpesvirus type-3 lineages using duplex PCR. J Virol Methods 158: 51-57

Bostock J, McAndrew B, Richards R, Jauncey K and others (2010) Aquaculture: global status and trends. Phil Trans R Soc Biol Sci 365:2897-2912

Costes B, Fournier G, Michel B, Delforge C and others (2008) Cloning of the koi herpesvirus genome as an infectious bacterial artificial chromosome demonstrates that disruption of the thymidine kinase locus induces partial attenuation in Cyprinus carpio koi. J Virol 82:4955-4964

Davison AJ, Kurobe T, Gatherer D, Cunningham C and others (2013) Comparative genomics of carp herpesviruses. J Virol 87:2908-2922

Haenen OLM, Way K, Bergmann SM, Ariel E (2004) The emergence of koi herpesvirus and its significance to European aquaculture. Bull Eur Assoc Fish Pathol 24: 293-307

Hanson L, Dishon A, Kotler M (2011) Herpesviruses that infect fish. Viruses 3:2160-2191

> Hara H, Aikawa H, Usui K, Nakanishi T (2006) Outbreaks of koi herpesvirus disease in rivers of Kanagawa Prefecture. Fish Pathol 41:81-83

Hedrick RP, Gilad O, Yun S, Spangenberg JV and others (1999) A herpesvirus associated with mass mortality of juvenile and adult koi, Cyprinus carpio. Fish Health Newsl 27:7 
Hedrick RP, Gilad O, Yun S, Spangenberg JV and others (2000) A herpesvirus associated with mass mortality of juvenile and adult koi, a strain of common carp. J Aquat Anim Health 12:44-57

Jung SJ, Miyazaki T (1995) Herpesviral haematopoietic necrosis of goldfish, Carassius auratus (L.). J Fish Dis 18: 211-220

Kurita J, Yuasa K, Ito T, Sano M and others (2009) Molecular epidemiology of koi herpesvirus. Fish Pathol 44:59-66

Sano T, Fukuda H, Furukawa M, Hosoya H, Moriya Y (1985) A herpesvirus isolated from carp papilloma in Japan. In: Ellis AE (ed) Fish and shellfish pathology. Academic Press, London, p 307-311

Sano T, Morita N, Shima N, Akimoto M (1991) Herpesvirus cyprini: lethality and oncogenicity. J Fish Dis 14:533-543

Sano M, Ito T, Kurita J, Yanai T, Watanabe N, Miwa S, Iida $\mathrm{T}$ (2004) First detection of koi herpesvirus in cultured common carp Cyprinus carpio in Japan. Fish Pathol 39: 165-167

Schubert GH (1966) The infective agent in carp pox. Bull Off Int Epizoot 65:1011-1022

Sunarto A, Taukhid, Rukyani A, Koesharyani I and others (2005) Field investigations on a serious disease outbreak among koi and common carp (Cyprinus carpio) in Indonesia. In: Walker P, Lester R, Bondad-Reantaso MG (eds) Diseases in Asian aquaculture V. Fish Health Section, Asian Fisheries Society, Manila, p 125-135

Tamura K, Peterson D, Peterson N, Stecher G, Nei M, Kumar S (2011) MEGA5: molecular evolutionary genetics analysis using maximum likelihood, evolutionary distance, and maximum parsimony methods. Mol Biol Evol 28: 2731-2739 doi:10.1093/molbev/msr121

> van Beurden SJ, Bossers A, Voorbergen-Laarman MH, Haenen OLM and others (2010) Complete genome sequence and taxonomic position of anguillid herpesvirus 1. J Gen Virol 91:880-887

Waltzek TB, Kelley GO, Stone DM, Way K and others (2005) Koi herpesvirus represents a third cyprinid herpesvirus (CyHV-3) in the family Herpesviridae. J Gen Virol 86: 1659-1667

Waltzek TB, Kelley GO, Alfaro ME, Kurobe T, Davison AJ, Hedrick RP (2009) Phylogenetic relationships in the family Alloherpesviridae. Dis Aquat Org 84:179-194

Wolf K (1988) Fish pox. In: Wolf K (ed) Fish viruses and fish viral diseases. Cornell University Press, Ithaca, NY, p 253-263 
Appendix. Comparison of the partial major capsid protein (MCP) gene sequence obtained from representatives of the CyHV variant strains with known cyprinid herpesviruses and anguillid herpesvirus 1 (AngHV-1). Results presented in a phylogenetic tree (Fig. A1) and an identity matrix (Table A1)

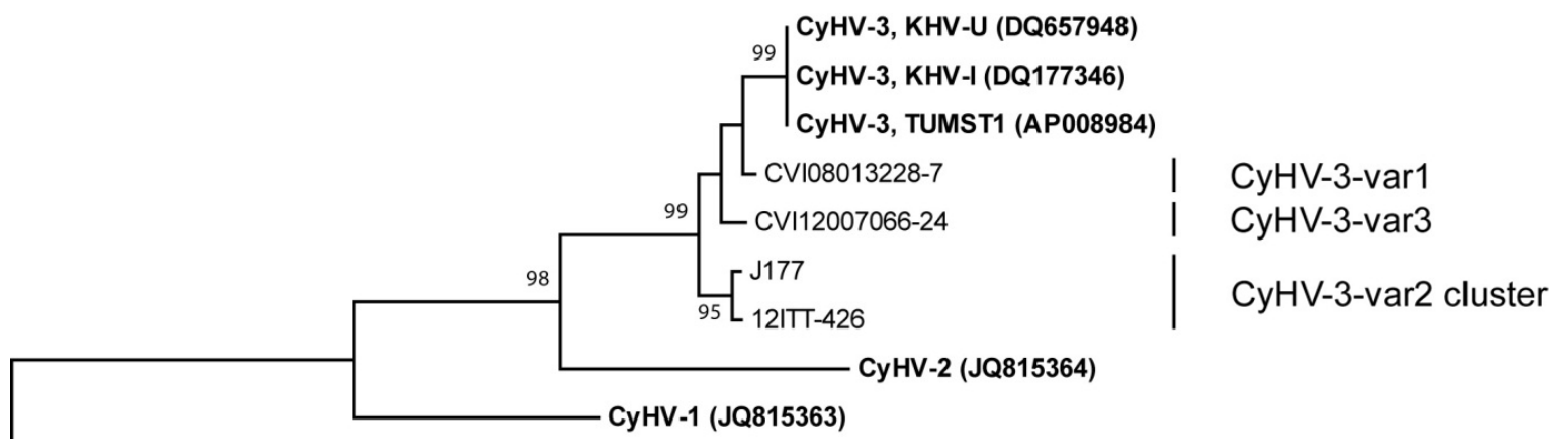

AngHV-1 (FJ940765)

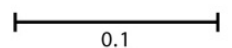

Fig. A1. Phylogenetic tree of partial major capsid protein gene sequences. Unrooted maximum likelihood tree based on partial (491 nt) major capsid protein gene sequences of the putative cyprinid herpesvirus (CyHV) strains. The tree with the highest log likelihood is shown. Bootstrap values (1000 replicates) of $>70 \%$ are indicated at the branch nodes. The tree is drawn to scale, with branch lengths measured in the number of substitutions per site. The known cyprinid herpesviruses are in bold, with GenBank accession numbers in brackets

Table A1. Identity between partial major capsid protein gene sequences (491 nt) of a selected number of the cyprinid herpesvirus 3 (CyHV-3) variant strains and known sequences of cyprinid herpesviruses and anguillid herpesvirus (AngHV-1). Expressed as percentage nucleotide identity (regular font) and deduced amino acid identity (in bold). Calculated using MEGA5. GenBank accession numbers of reference strains: CyHV-3 (KHV-U), DQ657948; CyHV-1, JQ815363; CyHV-2, JQ815364; and AngHV-1, FJ940765

\begin{tabular}{|lcccccccc|}
\hline & CyHV-3 & CVI08013228-7 & CVI12007066-24 & J177 & 12ITT-426 & CyHV-2 & CyHV-1 & AngHV-1 \\
\hline CyHV-3 & & $\mathbf{9 8 . 8}$ & $\mathbf{9 8 . 2}$ & $\mathbf{9 8 . 2}$ & $\mathbf{9 8 . 2}$ & $\mathbf{8 7 . 7}$ & $\mathbf{7 6 . 7}$ & $\mathbf{3 9 . 9}$ \\
CVI08013228-7 & 97.4 & & $\mathbf{9 8 . 8}$ & $\mathbf{9 9 . 4}$ & $\mathbf{9 8 . 8}$ & $\mathbf{8 7 . 7}$ & $\mathbf{7 6 . 1}$ & $\mathbf{3 9 . 9}$ \\
CVI12007066-24 & 96.1 & 97.4 & & $\mathbf{9 9 . 4}$ & $\mathbf{9 9 . 4}$ & $\mathbf{8 7 . 1}$ & $\mathbf{7 5 . 5}$ & $\mathbf{4 0 . 5}$ \\
J177 & 94.9 & 96.5 & 96.3 & & $\mathbf{9 9 . 4}$ & $\mathbf{8 7 . 1}$ & $\mathbf{7 5 . 5}$ & $\mathbf{4 0 . 5}$ \\
12ITT-426 & 94.9 & 96.5 & 96.1 & 99.2 & & $\mathbf{8 7 . 7}$ & $\mathbf{7 6 . 1}$ & $\mathbf{4 0 . 5}$ \\
CyHV-2 & 81.9 & 81.5 & 81.7 & 81.5 & 81.5 & & $\mathbf{8 1 . 0}$ & $\mathbf{3 9 . 3}$ \\
CyHV-1 & 75.6 & 75.8 & 76.4 & 76.2 & 76.2 & 72.7 & & $\mathbf{4 1 . 1}$ \\
AngHV-1 & 54.4 & 54.4 & 56.0 & 54.8 & 55.2 & 53.4 & 55.6 & \\
\hline
\end{tabular}

Editorial responsibility: Mark Crane, Geelong, Victoria, Australia
Submitted: June 6, 2013; Accepted: September 4, 2013

Proofs received from author(s): November 18, 2013 